\title{
Pedagogical Technology of Improving the Students' Viability Levels in the Process of Mastering Foreign Language
}

\author{
Nadezhda Dmitrienko ${ }^{1}$, Svetlana Ershova ${ }^{1}$, Tatiana Konovalenko ${ }^{1}$, Elvira Kutsova ${ }^{1} \&$ Elena Yurina ${ }^{1}$ \\ ${ }^{1}$ Institute of the Service and Entrepreneurship (Branch), Don State Technical University, Russia \\ Correspondence: Nadezhda Alekseevna, Institute of the Service and Entrepreneurship (Branch), Don State \\ Technical University 147 Shevchenko Street, 346501, Russia. E-mail: stilist4486@mail.ru
}

Received: December 12, 2014 Accepted: January 22, 2015 Online Published: January 29, 2015

doi:10.5539/ies.v8n2p204

URL: http://dx.doi.org/10.5539/ies.v8n2p204

\begin{abstract}
The article points out that the process of mastering foreign language stimulates students' personal, professional and cultural growth, improving linguistic, communicative competences and viability levels. A proposed pedagogical technology of modeling different communicative situations has a serious synergetic potential for students' self organized viability as a way of their self-realization in linguistic communicative creativity improving a quality of professional education. It is noted that a viable specialist must be ready to different social changes and hardships, to be autonomous and adaptable, flexible and sustainable, competent and competitive, to be able to take extraordinary decisions in different unpredictable vital situations. There is a dependence of developing personal psychological characteristics and professional, linguistic and communicative competences on the level of students' viability. The authors prove that a pedagogical technology of modeling communicative situations improves the students' viability level at technical universities of this country. It is underlined that this technology must be integrated part of personal and professional development of future specialists. In this regard the authors propose to change the purpose, quality of educational process and evaluating criteria of competent specialist with the help of students' viability criteria.
\end{abstract}

Keywords: viability, technology, self organization, consciousness, education process, mastering foreign language, subjective experience, modeling communicative situations

\section{Introduction-The Problem of Forming Students' Viability: Background}

It is noted that a lot of young people all over the world have low viability levels characterized by a person's disinterest in solving different personal, social and professional problems and goals. Usually it is characterized as passivity in realizing personal aims combined with low moral level, social and cultural standards.

It is pointed out that young people often feel indifference and apathy to the processes of planning and implementing different aims and perspectives in personal, social and professional spheres. The low viability level is pointed out to be a reason for ever increasing number of suicides among young people, and existing social, national problems among young people like violence, drugs, alcohol, smoking and so on. The solution of these problems determines the urgency of creating a unified pedagogical technology of improving the students' viability level.

So a unified pedagogical concept of improving students' viability level has a very important scientific, administrative and socio-political significance for the future development of our people, society and modern community.

Pedagogical process of forming viable specialists determines a student's personal, psychological and social readiness to overcome different challenges of modern reality and problems of the students' adapting to different production, social, cultural and economic conditions, to get over hardships and meet social, economic and industrial requirements to the specialists in the era of globalization. The problem is very important as a lot of human, personal values, moral and cultural standards are becoming vague.

The high competitiveness in modern society determines educational orientation to improve professional level, so it is pointed out that modern specialists must be ready to operate and manage complex social, economic and production processes and cope with modern social, industrial, economic challenges, to be ready to find effective decisions in different unpredictable situations and to take responsibility for the results. Some papers stress that 
these professional competences and personal characteristics can be formed in a significant communicative process improving students' viability levels.

It is pointed out that viability level is a person's integrated psychological system based on universal moral, cultural, professional, communicative competences, human values, cultural meaning and significance of education process, self control and personal motives of learning process determining a student's active position in communicative situations as awareness of personal and professional growth.

\section{Literature Review}

Viability in pedagogical and sociological researches has qualitative characteristics and can be determined as a criterion of assessing life quality in the current economic conditions, the quality level of educational process and the result of students' self-realization in any significant social or professional activity. The process of mastering foreign language is one of the most significant activities stimulating the development of cultural layer of students consciousness. It is noted that a person's consciousness contains moral, professional and cultural values and human significance of viability. The process of mastering foreign language helps a student to combine different human, moral values, cultural meanings in a unique picture of a viable system.

The process of forming students' viability is significant due to the students' age and physiological peculiarities. The most important peculiarity is a high potential of students' consciousness activity. It is due to the personal structures of consciousness activity a person can become a real subject of his own life, demonstrating high levels of viability.

The term viability is widely used in different scientific contexts, to characterize viability of a country, to demonstrate personal characteristics, to show the progress of a modern world community. It is usually described as a static quality of any system (a person, a communication, education and so on) and a dynamic process of personal development. Thus the process of mastering foreign language is a dynamic process of forming students' viability and as any dynamic process it has a lot of contradictions and complexities. They can be reduced when referring to pedagogical synergy as integrative self developed dynamic process of a system due to its internal ability to search a balance in different crisis situations.

There are a lot of constructs describing viability as a main human ability, (Leontiev, 1998), subjective vitality, (Aleksandrova, 2001, 2008), coping behavior in difficult situations, (Antsyferova, 2008), individual self-realization (Abulkhanova-Slavskaya, 1999, 2005), a social competitiveness (Emelyanov, 2007) a style of self-regulation (Morosanova, 2007), inner individual stability (Bohan, 2004), sense of coherence (Haynes, 2008), hardiness (Kobasa \& Maddi, 2006), resilience (Masten, 2008); life effectiveness (Cicchetti, 2005).

The difference in determining this concept can be explained by different purposes and various pedagogical approaches to scientific problems.

Some scientists point out that the process of improving students' viability can be organized as special psychological courses or methodological classes, special psychological or pedagogical supporting programs helping a person to overcome different hardships. But they do not solve this complex problem.

Thus analyzing a lot of scientific papers devoted to the problem of developing and improving viability levels we can come to the conclusion that it has not got an adequate pedagogical solution in pedagogic researches yet. The existing methods and programs of developing a person's viability level are rather narrow as they aimed to help young people to cope with some specific social problems and hardships (like unemployment), but they are interruptive and do not form a stable person's ability and can be useful as behavior adapting programs for specific group of people.

A lot of psychological methods and programs devoted to this problem were carried out by foreign authors (Klohnen, 1996, 2006; Bernard, 2008; Mowbray, 2010) though a lot of them have not been translated and adapted to conditions of a technical university of this country, most of them have not passed any validation procedures.

Thus to train viable specialists we need practical pedagogical technologies and additional assessing methods.

The range of approaches to the study of the concept let us determine students' viability as a basic inborn psychological and vital ability as a dynamic process of students' self organization in modeling communicative situations. The key position of forming students' viability is based on integration of personal, professional, linguistic competences. The students are the subjects of educational process to determine their limits, levels and perspectives of their self organized viability being active creators of personal vitality.

So there are some contradictions between the significance of improving students' viability and insufficient 
attention to forming viable specialists, the significance of forming students' viability and the lack of practical pedagogical methods and technologies to implement it in educational process of a technical university; human values and significance of students' viability and using inhuman traditional methods of forming it in the system of professional education.

So the complexity of pedagogical processes aimed to improve students' viability identifies urgent need to refer to pedagogical synergy. Thus the process of improving students' viability is a continuous pedagogical process of mastering foreign language where a technology of modeling communicative situations is a pedagogical tool of different levels of self organized students' viability based on developing professional, communicative, language competences. So, a pedagogical technology of improving students' viability is based on main theories: psychological systems (Klochko, 2009), trans-communicative theory (Kabrin, 2008) and self-developing systems. (Knyazeva, 2003, 2005).

The conceptual meaning of our research can be realized if we refer to the educational potential of modeling language communicative situations as a process of students' self organized viability.

Humanistic potential of modeling communicative situations (dialogue, communication tasks, etc.) stimulate students' consciousness activity-subjectivity, reflexivity, motivation, criticality, etc. As a result of this activity we can observe different levels of students' viability as new formed personal characteristics indicated different students' viability levels.

Thus, the external pedagogical means (technology, methods) create internal (motivation) levels of students' psychological readiness to self-organized vitality (expressed by internal activity of a system stimulated by various communicative situations). Pedagogical technology of modeling communicative situations is a system of developing students' professional, cultural and subjective experience of surviving in crisis situations and stimulating further development.

So different communicative situations are supposed to be important pedagogic conditions for different synergetic self organized processes appeared in a system as cumulative synergy effect to stimulate inner impulses of a system to balance and stability in crisis situations.

It is proved that the more developing perspectives a system have the higher level of viability it demonstrates.

Conceptual plan of our research determines three pedagogical components: methodological component determining the basic scientific meanings of modeling communicative situations as pedagogical technology of improving students' viability level; theoretical component demonstrating the ways of improving students' viability in modeling communicative situations and practical component explaining pedagogical methods and pedagogical conditions of improving students' viability.

The hypothesis of the research based on the assumption of the students' viability level to improve efficiency and quality of professional training, and its dependence on many conditions. The efficiency of students' viability level is likely to be guaranteed:

- if a pedagogical technology of modeling communicative situations contains pedagogical conditions for students' self-identity; self organization and self realization;

- if a pedagogical technology is based on humanistic approaches to the education based on universal human values, integration of professional, communicative and linguistic competences and personal characteristics stimulating students' self organized viability.

We defined a viable specialist on the basis of existing state standards as the main evaluating criteria and social and economic requirements to a specialist. In this case the process of forming students' viability is a concept educational technology of developing students' professional, linguistic and communicative competences, based on a set of individual personal characteristics, interests, moral standards and cultural values. Thus the aim of forming viable specialist in educational system meets personal interests and intentions, social, economic needs and modern requirements as a success person's socializing and comfort adapting to different vital conditions.

The process of forming students' viability is implemented as a significant pedagogical process of mastering moral, cultural and professional values, personal motivation system based on universal values, meanings and significant linguistic communicative situations, in accordance to students' abilities (tendencies) to self-congruence, partners' emphatic acceptance, subjective control and realistic functioning.

In this case the process of modeling communicative situations stimulates inner activity of students' consciousness (motivation, self control, empathy, reflection and others), determines the system of personal values and vital position and testifies different levels of students' viability. 
The dependence of improving person's viability in different stressful, even dangerous situations let us refer to pedagogical technology of modeling communicative situations with unpredictable results. Being involved in different communicative situations, the students experience emotional distress gaining subjective experience to cope with different stressful vital situations.

There are pedagogical conditions of effective modeling communicative situations: the communicative situations must be interesting to the students; they must contain a concept; the content of the communicative situations must be open to be added by a student's subjective experience; unpredictable communicative situations must stimulate the students' consciousness activity and must contain a problem.

\section{Material and Methods}

Changes taking place in contemporary society, made it necessary to combine usual educational phenomenon with new education meanings and values determined by a number of researchers as acquisition of human viability essence, individual's creative potential, and subjective experience.

The modern educational directions let us change the key pedagogical positions and approaches to the process of mastering foreign language as a humanistic pedagogical process of forming students' viability levels based on valuable orientation of communicative situations implemented in dialogues as main conditions of students' co-creative cultural activity in education environment of a technical university.

To become a competent specialist a student must have viable characteristics, to be open minded, autonomous, flexible and at the same time a sustainable psychological system capable to overcome hardships and to preserve and develop personal characteristics in hard vital circumstances as a tendency to self organization.

In the context of pedagogical synergy professional, linguistic and communicative competences can be realized in communicative activity due to a creative nature of modeling communicative situations as the process of gaining subjective experience in the process of generating and integrating special, professional, linguistic knowledge having a serious synergetic potential for self organization.

It is impossible to form students' viability using traditional method of direct knowledge transference as it is pointed out that students' viability level is based on values and senses. They can't be transferred by the teacher but obtained by students in effective communicative processes. So, a pedagogical technology of modeling communicative situations must be involved in pedagogical process to create pedagogical conditions for self-control, self motivation and self organization.

In accordance with the state documents and regulations the main requirements to students' professional training are based on the principles of humanization, cultural and personal orientation. These principles are included in pedagogical technology of modeling language communicative situations based on universal values of humanistic philosophy, pedagogy and psychology. These values develop cultural layers of consciousness ensuring a pedagogical support to improve students' viability as internal self-motivation, self-reflection, self-criticism and self-organization. The principles are implemented in modeling communicative situations and guarantee a personal and professional growth of a future specialist.

To solve the problems of forming students' viability a set of interrelated research methods were used. In the theoretical part the applied methods of historical and pedagogical comparative theoretical analysis of philosophical, psychological and pedagogical papers on the subject, methods of induction and deduction, system structure analysis were applied.

To study the fundamental concepts a lot of conceptual analysis were performed. Experimental part of the study was carried out on the method of observation (included and non included methods of observations), expert assessments, testing using techniques-self-actualizing test (SAT) (Shostrom, 2001), diagnostic levels of subjective control (Rotter, 2004); motivation; self-concept, creative self-development (Andreev, 2005); test questionnaire (Stolin \& Panteleev, 2001); methods-autonomy-dependence (Parygin, 2003).

For socio-psychological diagnosing different groups of students were observed at different stages of empirical studies, a lot of standardized questionnaires and tests (including a modified version of the methodology "The Interpersonal Support Evaluation List, General Population (Cohen \& Hoberman, 1983; Cohen, Mermelstein, Kamarck, \& Hoberman, 1985), the method of the "Strategy of social support", standardized questionnaires and tests; technique for diagnosing cognitive-behavioral coping strategies (Sizov, 2001); "The survey of coping" (developed by Lazarus \& Folkman, 2002) and adapted by (Kryukova \& Kuftyak, 2006, 2008); diagnostic tools; method of social adaptation diagnosis (Rogers \& Diamond, 1987, 2004) were used.

Experimental research was done at Don state technical university at the chair "Foreign languages". There were 
85 students of the control group and 90 students of the experimental group. The experiment has been conducted for three years; there were 525 students of 1 st, 2 nd and 3rd year for the entire period. As to diagnostic indicators there were three levels of students' self-organized viability expressed by pedagogical technology of creating conditions for students' consciousness activities-low, medium, high.

Each level is represented by a variety of indicators signaling about varying in levels of forming diagnostic qualities and features. The difficulty of diagnosing results of students' self organized viability was based in diagnostic procedure. Scientific approach to diagnosing students' viability levels determines the need not to measure only students' skills and abilities demonstrating higher students' viability levels, but also to identify conditions and results of modeling communicative situations to optimize the process of forming students' viability.

\section{The Progress and Outcomes of the Experiment}

Before the beginning of the experiment we determined criteria indicating characteristics of viable specialists: awareness of significance of social adapting, ability to a dialogue interaction, effective communication, tolerance to different language and national culture traditions; personal qualities; motivation, criticality, creativity, empirical view, communicative experience.

The analysis of these criteria was done on a basis of personal characteristics and features, professional, linguistic and communicative competences. Synergetic integrating principle establishes links between universal and personal values, universal and personal senses, cultural and personal meanings, contradictions in views and respect to a different opinion.

Thus communicative competences develop concrete vital abilities based on consciousness' activity to be convincing in arguments, to neutralize the opponent; to distinguish between moral values and technocratic content of communication (motivation); to express critical analyses of well-established facts (invariant), a specific point of view to a particular situation combining different points of view; to search and adapt new positions in communication, to use special skills of transferring significant information as energy exchange, to accelerate decision making process, to summarize communication situation; to be tolerant, especially to the people with opposite opinions, to be ready to tactful expression of personal position (criticality); ability to identify explicit and hidden sources of contradictions and problems, to regulate conflicts in communicative situations (collision); to overcome different contradictions between well known facts contained in communicative situations and a way of searching a personal position and a possible way out of changing circumstances of communicative situations; (creativity); express support and empathy to partners, to demonstrate and refresh professional knowledge, to avoid conflicts, to be ready to a compromise, to have a desire to understand another person (empathy). So, activity of students' consciousness can be easily fixed by the direct observation methods.

These levels can be characterized by frequency which is considered to evaluate the effectiveness of quantitative measurements occurring in students' consciousness when they work with experimental linguistic communicative material (modeling communicative situations).

To diagnose the appearance of students' viability levels, we tested actual level of student's development at a given moment of our experiment. The scope of personal development is a vivid demonstration of viable students' progress beginning from starting level of students' viability.

Having approved the pedagogical diagnostics of evaluating pedagogical technology effectiveness optimal pedagogical conditions of students' consciousness creative activity were proposed in accordance with theoretical model and expressed by viable criteria. A designed program of dynamic changes testifying about higher levels of development is represented as changing in students' consciousness, including purposes of experimental research, its phases, methods and collecting and processing data.

Thus, we can test the effectiveness of pedagogical technology based on two programs: a program of indirect indicators to determine the initial and final levels of students' viability in an experimental group and to diagnosing the development of basic structures of consciousness-self control, reflection, autonomy, criticality, motivation, self-regulation and others in a control group.

\section{Discussion}

The reference to indirect indicators is explained by a) indirect nature of proposed pedagogical means-technology of modeling communicative situations creating pedagogical conditions for actualizing personal structures of consciousness as a way of students' vital activity; b) students' consciousness activity is based on the level of personal self control. Different changes in self control levels can be measured statistically with the help of pedagogical techniques. 
The second program of measuring the students' viability level is quantitative method to be carried out with the help of direct indicators to diagnose the students' abilities and skills in the operational sequence-objective-verbal, as a type of students' self-organizing consciousness moving to the highest viable levels.

The reference to direct indicators was done due to: a) the activities of personal structures of students' consciousness by a direct empirical expression; b) the ability of consciousness to produce different "transformations" of modeling communicative situations in accordance with personal and subjective peculiarities and communicative experience.

The initial survey was conducted with each student at each scale (higher score is $100 \%$ ) changing the results into standard scores, the scores are the basis for the relevant forms depending on the average value which is $50 \%$, and the standard deviation is $10 \%$, so each scale has its own scope. To test students' self-actualization levels we have recommended test scores for the highest level is $60 \%$.and $40-45 \%$ recommended as low level indicators of students' self-actualization.

So we can see that each student has a definite increase in personal viable level in the end of experimental work, indicating personal qualities as students' self organized viability, (due to changes in personal structures of consciousness). A significant increase is seen among the students of experimental groups with high levels of development; in motivation is $(+11.2 \%$ compared with $1.4 \%$ in control group); and criticality is $(9.7 \%)$. Significant changes occurred in all measured characteristics and the parameters are ranged among positive results from low to middle levels (in experimental groups the average is $18.5 \%$ as compared with $1.3 \%$ in a control group). In general, the growth of positive indicators of students' viability level is about $+11.4 \%$ and $+27.6 \%$ (from low to medium level indicating personal development). In the control group the growth factor is $-2.2 \%$ to $+3.3 \%$ (Table. 1 ).

Table 1. The results of effectiveness of technology of modeling communicative situations

\begin{tabular}{|c|c|c|c|c|c|c|c|c|c|c|}
\hline \multirow[t]{2}{*}{ Scale } & \multicolumn{4}{|c|}{ Control group } & \multirow[t]{2}{*}{$\mathrm{t}$} & \multicolumn{4}{|c|}{ Experimental group } & \multirow[t]{2}{*}{$\mathrm{t}$} \\
\hline & M1 & D1 & M2 & D2 & & M1 & D1 & M2 & D2 & \\
\hline 1.Competitiveness in time & 2.66 & 7.1 & 7.2 & 2.68 & 0.71 & 7.8 & 2.75 & 7.9 & 2.81 & 0.42 \\
\hline 2. Support & 6.76 & 45.8 & 46.4 & 6.84 & 2.14 & 46.8 & 6.84 & 47.6 & 6.89 & 2.50 \\
\hline 3. Valuable orientation & 3.31 & 11.0 & 10.7 & 3.27 & 1.5 & 11.0 & 3.31 & 11.4 & 3.97 & 0.50 \\
\hline 4. Flexibility & 3.74 & 14.0 & 13.4 & 3.66 & 2.14 & 14.8 & 3.84 & 13.5 & 3.67 & 3.17 \\
\hline 5. Sensitivity & 2.64 & 7.0 & 6.5 & 2.54 & 1.56 & 6.4 & 2.52 & 6.7 & 2.58 & 1.25 \\
\hline 6. Spontaneity & 2.60 & 6.8 & 6.6 & 2.56 & 1.0 & 6.3 & 2.50 & 7.1 & 2.66 & 2.0 \\
\hline 7. Self respect & 2.94 & 8.7 & 8.4 & 2.89 & 0.43 & 8.6 & 2.93 & 9.2 & 3.03 & 1.90 \\
\hline 8. Synergy & 1.76 & 3.1 & 3.7 & 1.92 & 1.5 & 4 & 2 & 3.6 & 1.89 & 1.21 \\
\hline 9. Creativity & 2.50 & 6.3 & 7 & 2.64 & 1.89 & 6.1 & 2.46 & 6.5 & 2.54 & 1.43 \\
\hline
\end{tabular}

A general positive growth of students' viability level in experimental-groups is (average $+11.6 \%$ compared to high level of development in the control group where it is - $0.5 \%$ ); a positive growth of creative skills is recorded by direct indicators (the average is $12.8 \%$ for high-level of development, in the control group it is $1.8 \%$ ).

The obtained data of experimental research prove the effectiveness of pedagogical technology of modeling communicative situations. It should be emphasized that a little discrepancy existed between positive evaluating results. They represent a specific scientific interest and are likely to determine socio-cultural factors.

\section{Results}

In conclusion we present the main results of the research:

1) The process of mastering foreign language develops cultural layer of students' consciousness containing professional, cultural, moral values and meanings as main sources of improving students' viability levels. The humanistic potential of linguistic communicative situations is the way of developing and improving the students' viability level stimulated by activities of students' consciousness: self control, subjectivity, reflexivity, motivation, criticality, creativity etc, and indicating different levels of students' personal and professional growth as the main characteristics of a viable specialist. 
2) Pedagogical technology of modeling communicative situations aimed to improve the students' viability levels was worked out in our practical work and based on a pedagogical concept of integrating language, communicative and professional competences, personal features, personal values and professional characteristics. The main pedagogical principles are: subjectivity (a basis for subjective activity of students' consciousness) problematic (a communicative situation must contain a problem), dialogue orientation, (a communicative situation is a dialogue of a teacher and a student, a dialogue between a subject and object) collision (to stimulate students' communicative creativity) as pedagogical concept of self organized students' viability.

3) The pedagogical concept is a pedagogical technology to overcome existing contradictions between the requirements, needs, interests and significance of improving the students' viability level and the way of its practical realization and implementation in educational environment of a technical university.

4) Experimental data demonstrate a significant growth of students' viability levels expressed as students' personal tendencies to self actualization, subjective control, realistic functioning and self organization.

We can say that the researching has a lot of perspectives for students' personal and professional development.

\section{Conclusion}

The research proved that pedagogical technology of modeling communicative situations is the effective way of improving students' viability. As a result of the research several recommendations on effective synergetic pedagogical conditions of improving students' viability were made. .The characteristic features of viable experts were pointed out, the significance of developing and improving the students' viability levels in educational environment of technical university is stressed.

The necessity of going on the research work will help us to investigate the process of improving person's viability at different stages of educational process at different subjects to testify a unified pedagogical concept of improving students' viability levels.

\section{Acknowledgements}

The research was conducted due to personal support of the Rector of Don state technical university, the Doctor of Technical Sciences, Professor Meshy B. Ch., the director of the Institute of service and business professor Stradanchenko S. G., all teachers of our chair.

\section{References}

Aleksandrova, L. A. (2004). To the concept of resilience in psychology. In M. M. Gorbatova, A. V. Seriy, \& M. S. Yanitskiy (Eds.), Siberian psychology today: Col. Scien. Works (Vol. 2, pp. 82-90).

Barton, P. T., Roland, R. R., Picano, J. J., \& Williams, T. J. (2008). Psychological Hardiness Predicts Success in USA Army Special Forces Candidates. International Journal of Selection and Assessment, 16(1), 78-81.

Budanov, V. G. (2007). Methodology for synergy in post non-classical science and education. M.: Publishing House of the LCI.

Dmitrienko, N. A. (2008). Self organization as a factor of self-identity. Pedagogy: family-school-community: monograph [OÜ Afanasyev, AK Baylikova et al.].

Guryanova, M. P. (2004). Parenting a viable identity in a disharmonious society. Pedagogika, 1, 18.

Klag, S., \& Bradley, G. (2004). The Role of hardiness in stress and illness: An exploration of the effect of negative affectivity and gender. British Journal of Health Psychology, 9, 137-161.

Klochko, V. E. (2000). Man as a self-organizing system of psychological. Man as a self-organizing psychological system: Materials region (pp. 3-7). Conf. Barnaul State Pedagogical University Publishing House.

Klochko, V. E. (2005). Self-organization in psychological systems: Problems of formation of the mental space of the person (Introduction to transspective analysis). Tomsk: Publishing house of Tomsk State University.

Knyazeva, E. N. (2003). Balancing on the edge of chaos as a way of creative renewal synergetic paradigm. Man and society in conditions of instability (pp. 123-140).

Konopkin, O. A. (2007). Mechanisms of conscious self-regulation of any human activity. In V. I. Morosanova (Ed.), Subject and personality psychology of self-regulation: Sat. scientific (pp. 12-31). Moscow, Stavropol: Publishing House of the PI RW NCSTU.

Kulnevich, S. V. (2001). Pedagogy of the person from concept to technology: Proc. Benefits. Rostov-on-Don.

Leontev, D. A., \& Mandrikova, E.Y. (2005). Simulation of "existential dilemma": An empirical study of personal 
choice. Psychology, 4, 37-42. Vestnik Moscow. Univ. Ser. 14.

\section{Copyrights}

Copyright for this article is retained by the author(s), with first publication rights granted to the journal.

This is an open-access article distributed under the terms and conditions of the Creative Commons Attribution license (http://creativecommons.org/licenses/by/3.0/). 